\title{
PERANCANGAN APLIKASI DATA MINING TRANSAKSI PENJUALAN UNTUK MENGETAHUI POLA BELI KONSUMEN PADA TOKO SINGGALANG PADANG MENGGUNAKAN ALGORITMA APRIORI BERBASIS WEB
}

\author{
Nelisa, Aulia Fitrul Hadi \\ Universitas Putra Indonesia YPTK Padang \\ Email : nelisanasution24@gmail.com,fitrulhadi@upiyptk.ac.id
}

\begin{abstract}
It takes a method or technique that can transform mountains of data into a valuable information or knowledge (knowledge) that are useful to support business decision making. Therefore in this paper association analysis application developed for extracting and interpreting the pattern of trend of sales of goods are often sold simultaneously from the transaction data using algorithms apriori.

Apriori algorithms will from a frequent itemset as predetermined based on two parameters, support and confidence, to find the rules of the association between a combination of items. Knowledge of a product can be used by companies to increase production ansd sales of a product.
\end{abstract}

Keywords: Data Mining, Algorithm Apriori, the Association Rules, Sales.

\section{Pendahuluan}

Data mining adalah proses mencari pola atau informasi menarik dalam data terpilih dengan menggunakan teknik atau metode tertentu. Teknik, metode, atau algoritma dalam data mining sangat bervariasi. Pemilihan metode atau algoritma yang tepat sangat bergantung pada tujuan dan proses KDD secara keseluruhan (Jayapana, 2015).

Data penjualan yang sudah ada akan diolah atau dianalisis untuk mengetahui tingkat kecenderungan konsumen di setiap tempat tujuan pemasaran produk pada faktor ketertarikannya. Dari pengolahan data tersebut akan diperoleh suatu pola konsumsi masyarakat terhadap produk dari perusahaan tersebut.

\section{Landasan Teori}

\subsection{Definisi Data Mining}

Data mining adalah proses yang menggunakan teknik statistik, matematika, kecerdasan buatan, dan machine learning untuk mengekstraksi dan mengidentifikasi informasi yang bermanfaat dan pengetahuan yang terkait dari berbagai database besar. Istilah data mining memiliki hakikat sebagai disiplin ilmu yang tujuan utamanya adalah untuk menemukan, menggali, atau menambang pengetahuan dari data atau informasi yang kita miliki. Data mining, sering juga disebut sebagai Knowledge Discovery in Database (KDD). KDD adalah kegiatan yang meliputi pengumpulan, pemakaian data, historis untuk menemukan keteraturan, pola atau hubungan dalam set data berukuran besar (Jurnal : Mujib Ridwan, dkk 2013).

Sebagai suatu rangkaian proses, data mining dapat dibagi menjadi beberapa tahap proses yang diilustrasikan pada Gambar 2.4. Tahap-tahap tersebut bersifat interaktif, pemakai terlibat langsung atau dengan perantaraan knowledge base (Jurnal : Mujib Ridwan, dkk 2013). 


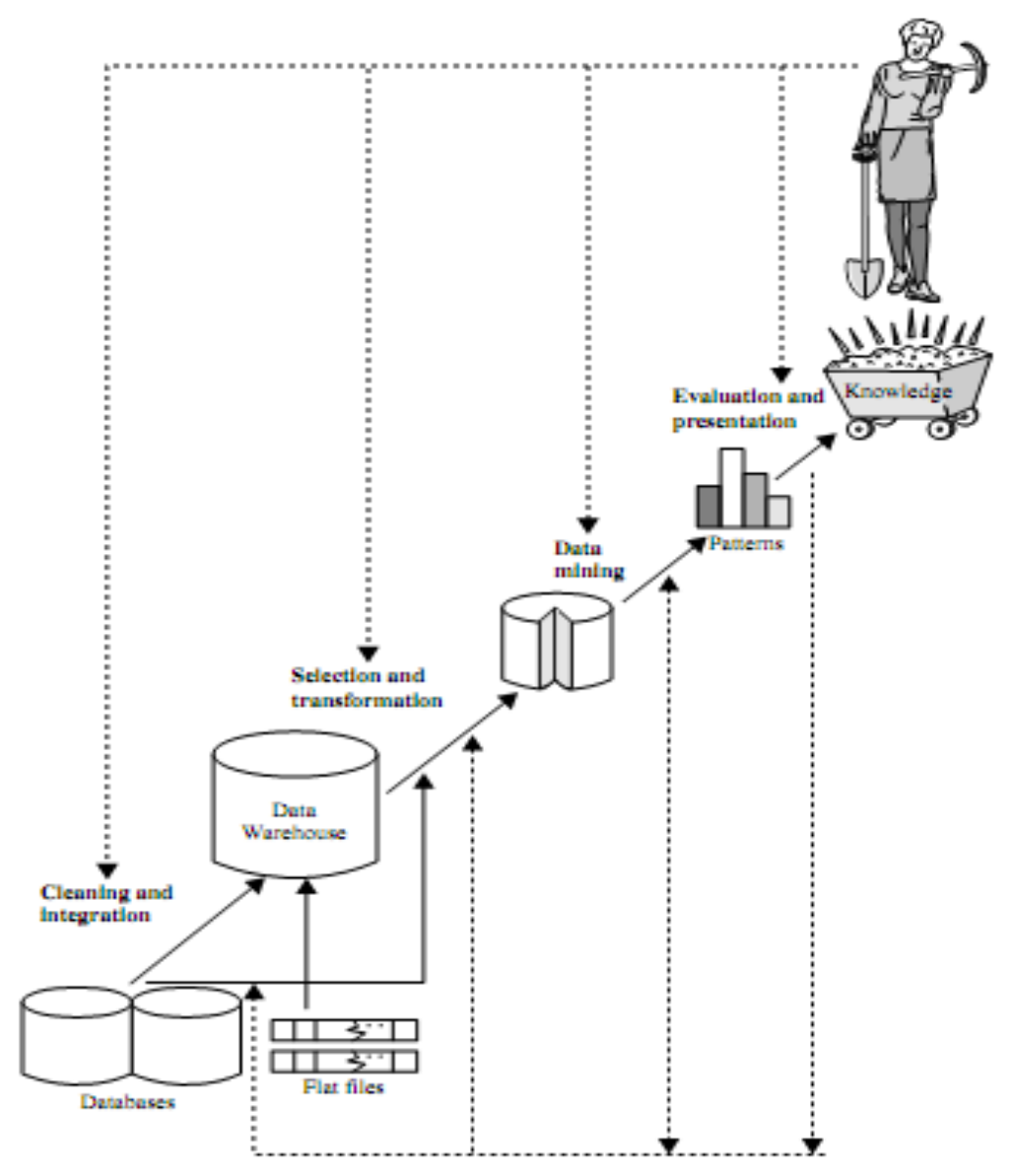

\section{Gambar 2.4 Tahapan-Tahapan Data Mining}

Tahap-tahap data mining adalah sebagai berikut:

1. Pembersihan data (data cleaning)

Pembersihan data merupakan proses menghilang-kan noise dan data yang tidak konsisten atau data tidak relevan.

2. Integrasi data (data integration)

Integrasi data merupakan penggabungan data

dari berbagai database ke dalam satu database baru.

3. Seleksi data (data selection)

Data yang ada pada database sering kali tidak semuanya dipakai, oleh karena itu hanya data yang sesuai untuk dianalisis yang akan diambil dari database.

4. Transformasi data (data transformation)

Data diubah atau digabung ke dalam format yang sesuai untuk diproses dalam data mining.

5. Proses mining

Merupakan suatu proses utama saat metode diterapkan untuk menemukan pengetahuan berharga dan tersembunyi dari data.

6. Evaluasi pola (pattern evaluation)

Untuk mengidentifikasi pola-pola menarik kedalam knowledge based yang ditemukan.

7. Presentasi pengetahuan (knowledge presentation) 
Merupakan visualisasi dan penyajian pengetahuan mengenai metode yang digunakan untuk memperoleh pengetahuan yang diperoleh pengguna (Jurnal : Mujib Ridwan, dkk 2013).

\subsection{Teknik Data Mining}

Beberapa teknik dan sifat Data mining, yaitu (Fajar. 2013:14) :

1. Classification

Klasifikasi ( Classification) adalah proses untuk menemukan model atau fungsi yang menjelaskan untuk menemukan model atau fungsi yang menjelaskan atau membedakan konsep atas kelas data, dengan tujuan untuk dapat memperkirakan kelas dari suatu obyek yang labelnya tidak diketahui.. ( Wahyu Pramusinto, William Budi Utama Gunamawan, $2013: 2$ ).

2. Clustering

Mempartisi data-set menjadi beberapa sub-set atau kelompok sedemikiann rupa sehingga elemen-elemen dari suatu kelompok tertentu memiliki set properti yang dishare bersama, dengan tingkat similaritas yang tinggi dalam suatu kelompok dan tingkat similaritas antar kelompok yang rendah. Disebut juga unsupervised learning (Fajar. 2013).

3. Association Rule Discovery

Analisis asosiasi adalah teknik mining untuk menemukan aturan asosiatif antara suatu kombinasi item. analysis ( Wahyu Pramusinto, William Budi Utama Gunamawan, $2013: 2$ ).

4. Sequential Pattern Discovery

Mencari sejumlah event yang secara umum terjadi bersama-sama.

5. Regression

Memprediksi nilai dari suatu variable kontinyu yang diberikan berdasarkan nilai dari vairable yang lain, dengan mengansumsikan sebuah model ketergantungan linier atau nonlinier. Teknik ini dipelajari dalam statistika, bidang jaringan saraf tiruan (neural network) (Fajar. 2013).

\section{Metodologi Penelitian}

Kerangka penelitian penelitian ini salah satu metode yang dapat memudahkan seorang peneliti dalam menyelesaikan laporan dan penelitian adalah dengan menyusun sebuah kerangka penelitian, agar penelitian tidak keluar dari objek yang akan di teliti Adapun kerangka penelitian yang penulis lakukan dapat tergambar seperti bagan dibawah ini.

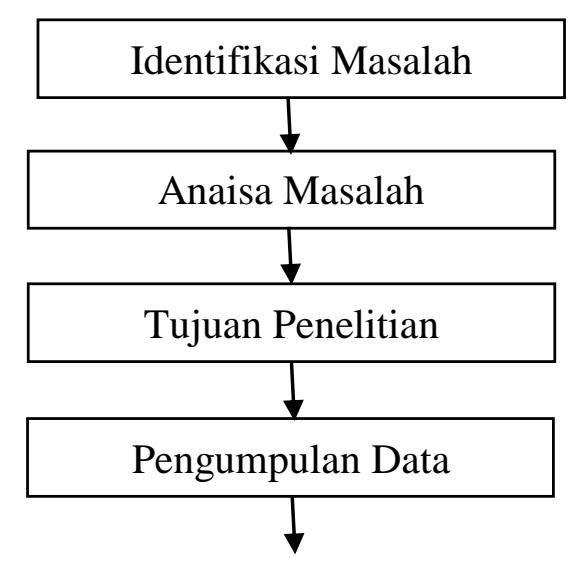




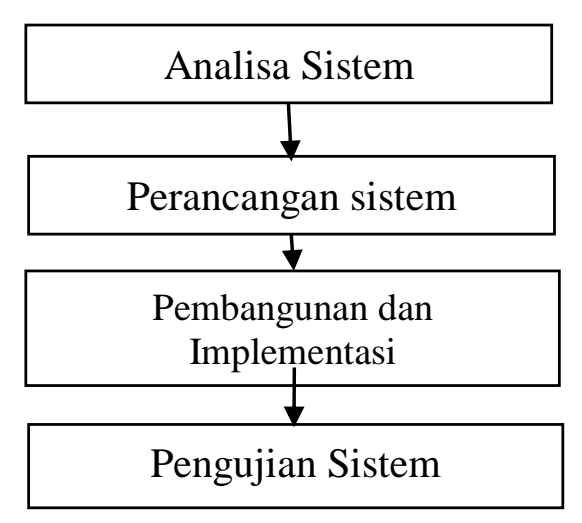

\section{Gambar 3.1 Kerangka kerja Penelitian}

\section{Analisa dan Pengolahan Data}

\subsection{Analisa Data Mining dengan Algoritma Apriori}

Analisa data merupakan tahap melakukan penganalisaan terhadap data penjualan yang diperlukan untuk perancangan system, pada penganalisa dilakukan pengolahan data sesuai dengan ketentuan rumus yang telah ditetapkan.

Dimana dalam proses perhitungannya hanya data transaksi penjualan yang akan diolah dalam algoritma apriori, aturan asosiasi dilaksanakan dalam 2 langkah proses, yaitu:

1. Temukan semua frequency itemset ; Berdasarkan defenisi, masing - masing dari itemset maka muncul sedikitnya dengan frequency sebesar diberikan dalam minimum support count.

2. Munculkan strong association rule dari frequency itemset, Berdasarkan defenisi, aturan ini harus memenuhi minimum support dan minimum confidence.

Adapun data-data yang dipelukan dalam penelitan ini dapat dilihat pada tabel 4.1 berikut:

\begin{tabular}{|c|l|}
\hline Id Transaksi & \multicolumn{1}{|c|}{ Item yang dibeli } \\
\hline 1 & $\begin{array}{l}\text { Gery Salut, Roma Malkist, Nescafe Original, Aqua, Fruit Tea, Pulpy } \\
\text { Orange, Milo, Sari Roti. }\end{array}$ \\
\hline 2 & Milo, Sampurna 16, Mizone, FOX 90G, Bear Brand. \\
\hline 3 & $\begin{array}{l}\text { Pulpy Orange, Kopiko, Oreo Mini, Astor Wafer, Chunky Bar, } \\
\text { Marlboro. }\end{array}$ \\
\hline 4 & $\begin{array}{l}\text { Tango Wafer, Taro Net, Djava Young Bakery, Ohayo Bakery, Qtela, } \\
\text { Putri Chania Pukis, Koko Krunch Combo. }\end{array}$ \\
\hline 5 & Aqua, Lasegar, Bear Brand, Buavita, Fanta Strawbery. \\
\hline 6 & $\begin{array}{l}\text { Aqua, Peyek Anugrah, Ohayo Bakery, Teh Pucuk, Aim Biskuit Crispy, } \\
\text { Putri Chania Pukis, Tebs Tea Cooler, Sari Roti, MM Nutriboost. }\end{array}$ \\
\hline 7 & Teh Botol, Milo, Nescafe Latte, Mkp Cap Lang. \\
\hline 8 & $\begin{array}{l}\text { Aqua, Pulpy Orange, Kopiko, Astor Wafer, Chunky Bar, Marlboro } \\
\text { Light. }\end{array}$ \\
\hline 9 & $\begin{array}{l}\text { Tango Wafer, Taro Net, Djava Young Bakery, Ohayo Bakery, Qtela, } \\
\text { Putri Chania Pukis, Koko Krunch. }\end{array}$ \\
\hline 10 & Aqua, Lasegar, Bear Brand, Buavita, Fanta Strawbery. \\
\hline 11 & $\begin{array}{l}\text { Aqua, Peyek Anugrah, Ohayo Bakery, Teh Pucuk, Lays, Kist Mint, } \\
\text { Aim Biskuit Crispy, Putri Chania Pukis, Tebs Tea, Sari Roti, MM } \\
\text { Nutriboost. }\end{array}$ \\
\hline 12 & Cheetos, Ohayo Bakery, Aqua, Teh Botol, Kopiko, Hexos. \\
\hline 13 & Sampurna 16, Proman Energenesis, Bear Brand. \\
\hline
\end{tabular}




\begin{tabular}{|c|c|}
\hline 14 & $\begin{array}{l}\text { Teh Pucuk, Monde Butter Cookies, Inaco Jelly, Fruit Tea, Indomie } \\
\text { Kari Ayam, Biskuat Coklat. }\end{array}$ \\
\hline 15 & $\begin{array}{l}\text { Chitato, Lotte Koala's March, Koala March, Harapan Baru, Kacang } \\
\text { Garuda, Mini Corneto Vanila, Silver Queen Black, M-150, Restu } \\
\text { Bunda, Peyek Dua Putri, Chips Ahoy, Super Duluxe. }\end{array}$ \\
\hline 16 & Aqua, Ohayo Bakery, Hexos, Abc Sari Kacang, Shanty Keripik Balado. \\
\hline 17 & Populaire Stro-Van, PP.Rainbow Power, Lactogen, Clas Mild 16. \\
\hline 18 & $\begin{array}{l}\text { Lasegar, Harapan Baru, Kacang Klt Garuda Bawang, Charm Bf Extra } \\
\text { Maxi 8, Walls Feast Chocolate, Paddle Pop Fruity, Cheetos, Orange } \\
\text { Water, Chunky Bar, Fruit Tea, Teh Botol. }\end{array}$ \\
\hline 19 & Fruit Tea, Kopiko, Rexona Men Ico Cool, Lays. \\
\hline 20 & Sampurna $16, \mathrm{M}-150$. \\
\hline 21 & $\begin{array}{l}\text { Populaire Stro-Van, Sari Roti, Lays, Lara Kue Bawang, Mytea, } \\
\text { Sampurna 16, Yazumi Bakery, Pulpy Orange, Silver Queen Silver, } \\
\text { Aqua. }\end{array}$ \\
\hline 22 & Hexos, Antimo, Paddle Pop Shaky Shake, Aqua. \\
\hline 23 & Sari Roti, Paddle Pop Shaky Shake, Mytea. \\
\hline 24 & $\begin{array}{l}\text { Aqua, Teh Pucuk, Lays, Kopiko, You C1000 Orange, Pulpy Orange, } \\
\text { Cheetos, Monde Butter Cookies, Fitbar Coklat, Paseo Smart Refil, } \\
\text { Tango Wafer. }\end{array}$ \\
\hline 25 & $\begin{array}{l}\text { Sampurna 16, Tango Wafer, Niss Lemonia, Good Time Precious, Bear } \\
\text { Brand, Lays, Kacang Garuda. }\end{array}$ \\
\hline 26 & Rexona Ro, Orange Water. \\
\hline 27 & $\begin{array}{l}\text { Lays, Paddle Pop Ocean, Tango Wafer, PP.Choco Magma, Boom Pot } \\
\text { Mint, Populaire Cup Choc-Vanila, Frestea Melati, Sweety Xl } 8 \text { Extra, } \\
\text { Faajar Kerupuk Bawang, Lolipop Pelangi Kecil. }\end{array}$ \\
\hline 28 & $\begin{array}{l}\text { Antangin Permen, Restu Bunda, Fajar Kerupuk Bawang, Pulpy Orange, } \\
\text { Aqua. }\end{array}$ \\
\hline 29 & Paddle Pop Color Poper, Paddle Pop Roket Jely. \\
\hline 30 & $\begin{array}{l}\text { Aqua, Garuda KCG Atom Manis, Lara Kue Bawang, Nescafe Latte, } \\
\text { Chitato, Rifa Snack Kue Arai Pinang, Pulpy Orange, Sum Ayu S Sirih. }\end{array}$ \\
\hline 31 & $\begin{array}{l}\text { J.A Styl Cream, Vaseline Hbl, Axe 150, Kinder, Mb Lotion, Milna } \\
\text { Biskuit, Pepsodent 120, Indomie Kari Ayam, Indomie Goreng, } \\
\text { Indofood Sambal, Teh Botol, Ohayo Bakery. }\end{array}$ \\
\hline 32 & Aqua, Paddle Pop Fruity Zap, PP.Rainbow Power. \\
\hline 33 & $\begin{array}{l}\text { Fajar Kerupuk Bawang, Peyek Anugrah, Snack Ball Jagung, Putri } \\
\text { Chania Pukis, Teh Botol, Restu Bunda, Chesse Ring. }\end{array}$ \\
\hline 34 & Clas Mild 16, Dunhil Filter 16, Garnier Light Spf. \\
\hline
\end{tabular}

\subsection{Analisa Pola Frekuensi Tinggi}

\section{Tabel 4.1 Tabel Transaksi}

Tahap ini mencari kombinasi item yang memenuhi syarat minimum dari nilai support dalam database. Nilai support sebuah item diperoleh dengan rumus berikut :

$$
\text { Support }(A)=\frac{\text { Jumlah transaksi mengandung } A}{\text { Total Transaksi }}
$$

Nilai support dari 2 item diperoleh dengan menggunakan rumus :

$$
\text { Support }(A, B)=P(A \cap B)
$$

$$
\text { Support }(A, B)=\frac{\sum \text { Transaksi mengandung } A \text { dan } B}{\sum \text { Transaksi }}
$$


Setiap transaksi mempertasikan himpunan item yang berada dalam himpunan item yang dijual. Aturan yang kuat adalah aturan - aturan yang melebihi kriteria support dan confidence minimum. Misalnya seorang analisis menginginkan aturan yang memiliki suppoort lebih dari $10 \%$ dan confidence lebih dari $10 \%$. Sebuah itemset adalah himpunan item - item yang ada dan $k$-itemset adalah itemset yang berisi $k$-item dan $\{\mathrm{A}, \mathrm{B}, \mathrm{C}\}$ merupakan 3 itemset.

Frequent itemset adalah itemset yang terjadi paling sedikit pada jumlah tertentu, ditentukan dengan banyak transaksi yaitu 34 dibagi dengan banyak item barang pada transaksi, sehingga dapat dicari dengan rumus :

$$
\text { Support }(A)=\frac{\text { Jumlah transaksi mengandung } A}{\text { Total Transaksi }}
$$

Untuk $\mathrm{k}=2$ ( 2 item), dari setiap item yang melewati support $30 \%$ akan dicari frequent itemset masing - masing item Nilai support dan 2 item diperoleh dengan menggunakan rumus

$$
\begin{gathered}
\text { Support }(\mathrm{A}, \mathrm{B})=\mathrm{P}(\mathrm{A} \cap \mathrm{B}) \\
\text { Support }(A, B)=\frac{\sum \text { Transaksi mengandung A dan B }}{\sum \text { Trasaksi }}
\end{gathered}
$$

Dari data yang sudah di masukan dan nilai dari minimum support yang telah ditentukan yaitu $10 \%$, dan minimum confidence $10 \%$, maka item yang mempunyai nilai minimum support diatas dari $10 \%$ dan nilai minimum confidence $10 \%$, maka item tersebut yang akan di ambil untuk menentukan nilai frequent itemset.

\subsection{Pembentukan Aturan Asosiasi}

Setelah semua pada frekuensi tinggi ditemukan, barulah dicari aturan asosiasi yang memenuhi syarat minimum untuk confidence dengan menghitung confidence aturan asosiatif $\mathrm{A} \rightarrow \mathrm{B}$.

Nilai confidence dari aturan $\mathrm{A} \rightarrow \mathrm{B}$ diperoleh dari rumus berikut:

$$
\begin{aligned}
& \text { Confidence }=\mathrm{P}(\mathrm{B} \mid \mathrm{A})=\frac{\sum \text { Transaksi mengandung A dan } \mathrm{B}}{\sum \text { Transaksi mengandung } \mathrm{A}} \\
& \text { Confidence }=\mathrm{P}(5 \mid 49)=\frac{\sum(\text { Aqua,Lays })}{\sum \text { Aqua }}=\frac{0,12}{0,41}=0,29=29 \% \\
& \text { Confidence }=\mathrm{P}(49 \mid 5)=\frac{\left.\sum \text { (Lays,Aqua }\right)}{\sum \text { Lays }}=\frac{0,12}{0,18}=0,67=67 \% \\
& \text { Confidence }=\mathrm{P}(5 \mid 67)=\frac{\sum(\text { Aqua, Ohayo Bakery })}{\sum \text { Aqua }}=\frac{0,12}{0,41}=0,29=29 \% \\
& \text { Confidence }=\mathrm{P}(67 \mid 5)=\frac{\left.\sum \text { (Ohayo Bakery,Aqua }\right)}{\sum \text { Ohayo Bakery }}=\frac{0,12}{0,21}=0,57=57 \% \\
& \text { Confidence }=\mathrm{P}(5 \mid 85)=\frac{\left.\sum \text { (Aqua, } \text { Pulpy Orange }\right)}{\sum \text { Aqua }}=\frac{0,18}{0,41}=0,44=44 \% \\
& \text { Confidence }=\mathrm{P}(85 \mid 5)=\frac{\left.\sum \text { (Pulpy Orange,Aqua }\right)}{\sum \text { Pulpy Orange }}=\frac{0,18}{0,21}=0,86=86 \% \\
& \text { Confidence }=\mathrm{P}(5 \mid 94)=\frac{\left.\sum \text { (Aqua,Sari Roti }\right)}{\sum \text { Aqua }}=\frac{0,12}{0,41}=0,29=29 \% \\
& \text { Confidence }=\mathrm{P}(94 \mid 5)=\frac{\sum(\text { Sari roti,Aqua })}{\sum \text { Sari roti }}=\frac{0,12}{0,15}=0,80=80 \% \\
& \text { Confidence }=\mathrm{P}(67 \mid 86)=\frac{\sum(\text { Ohayo Bakery,Putri Chania Pukis })}{\sum \text { Ohayo Bakeri }}=\frac{0,12}{0,21}=0,57=57 \% \\
& \text { Confidence }=\mathrm{P}(86 \mid 67)=\frac{\sum(\text { Putri Chania Pukis,Ohayo Bakery })}{\sum \text { Putri Chania Pukis }}=\frac{0,12}{0,15}=0,80=80 \%
\end{aligned}
$$


Hasil pencarian untuk confidence yang didapat dari perhitungan kombinasi 2 itemset yang terdapat pada Tabel 4.2 berikut ini :

\begin{tabular}{|c|c|c|}
\hline Knowledge & Confidence & Persentase \\
\hline $\begin{array}{l}\text { - Jika konsumen membeli Aqua, } \\
\text { maka membeli Lays }\end{array}$ & 0,29 & $29 \%$ \\
\hline $\begin{array}{l}\text { - Jika konsumen membeli Lays, } \\
\text { maka membeli Aqua }\end{array}$ & 0,67 & $67 \%$ \\
\hline $\begin{array}{l}\text { - Jika konsumen membeli Aqua, } \\
\text { maka membeli Ohayo Bakery }\end{array}$ & 0,29 & $29 \%$ \\
\hline $\begin{array}{l}\text { - Jika konsumen membeli Ohayo } \\
\text { Bakery, maka membeli Aqua }\end{array}$ & 0,57 & $57 \%$ \\
\hline $\begin{array}{l}\text { - Jika konsumen membeli Aqua, } \\
\text { maka membeli Pulpy Orange }\end{array}$ & 0,44 & $44 \%$ \\
\hline $\begin{array}{l}\text { - Jika konsumen membeli Pulpy } \\
\text { Orange, maka membeli Aqua }\end{array}$ & 0,86 & $86 \%$ \\
\hline $\begin{array}{l}\text { - Jika konsumen membeli Aqua, } \\
\text { maka membeli Sari Roti }\end{array}$ & 0,29 & $29 \%$ \\
\hline $\begin{array}{l}\text { - Jika konsumen membeli Sari } \\
\text { Roti, maka membeli Aqua }\end{array}$ & 0,80 & $80 \%$ \\
\hline $\begin{array}{l}\text { - Jika konsumen membeli Ohayo } \\
\text { Bakery, maka membeli Putri } \\
\text { Chania Pukis }\end{array}$ & 0,57 & $57 \%$ \\
\hline $\begin{array}{l}\text { - Jika konsumen membeli Ohayo } \\
\text { Bakery, maka membeli Jika } \\
\text { konsumen membeli Putri Chania } \\
\text { Pukis, maka membeli Ohayo } \\
\text { Bakery }\end{array}$ & 0,80 & $80 \%$ \\
\hline
\end{tabular}

Tabel 4.2 Tabel Knowledge

\section{Kesimpulan}

Dari penulisan tugas akhir ini mulai dari tahapan analisa permasalahan yang ada, hingga pengujian aplikasi sistem maka dapat diambil beberapa kesimpulan yaitu:

1. Data Mining dapat di implementasikan dengan menggunakan database penjualan produk barang untuk dapat menemukan kecenderungan pola kombinasi itemsets sehingga dapat dijadikan sebagai informasi untuk mengetahui prilaku konsumen dalam membeli produk barang secara bersamaan.

2. Aplikasi ini juga sebagai alternative alat bantu keputusan dalam menentukan penempatan barang diarea yang saling berdekatan sesuai prilaku konsumen dalam membeli barang secara bersamaan, membantu untuk mengetahui produk barang yang jarang dibeli konsumen dan sebagai alat alternative 
dalam meningkatkan strategi pemasaran dengan cara membuat diskon barang tertentu yang jarang di beli untuk menarik minat beli konsumen.

3. Dengan menerapkan aplikasi data mining menggunakan metode association rules ini dapat mengetahui bahwa prduk yang paling tinggi lah persentase terjualnya maka produk tersebutlah yang akan ditingkatkan agar konsumen terpenuhi keinginannya.

4. Dengan menerapkan aplikasi data mining menggunakan metode association rules ini dapat mempermudah karyawan dalam memberikan laporan transaksi dengan cepat dan tepat terhadap pemimpinnya agar pimpinan dapat memberikan keputusan cepat dan tepat

\section{Daftar Pustaka}

[1]. Hermawati, Fajar Astuti. "Data Mining. 2013." ANDI: Yogyakarta.

[2]. RIANGgA, JAYAPANA DUTA. "Analisis Pola Pembelian Konsumen Dengan Algoritma Apriori Pada Data Transaksi Penjualan Obat Di Apotek Rahayu Jepara." Skripsi, Fakultas Ilmu Komputer (2015).

[3]. Ridwan, Mujib, Hadi Suyono, and M. Sarosa. "Penerapan Data Mining Untuk Evaluasi Kinerja Akademik Mahasiswa Menggunakan Algoritma Naive Bayes Classifier." Jurnal EECCIS : 59-64.

[4]. Pramusinto, Wahyu, and William Budi Utama Gunawan-Universitas Budi. "Implementasi Algoritma Apriori untuk Aplikasi Data Mining Informasi Manfaat Asuransi Jiwa Studi Kasus: Pada PT Azarel Jelia Sejahtera." Jurnal TICom 2.1 (2013).

[5]. Hadi, A. F. (2017). ANALISIS DATA MINING UNTUK MENENTUKAN VARIABEL-VARIABEL YANG MEMPENGARUHI KELAYAKAN KREDIT KEPEMILIKAN RUMAH MENGGUNAKAN TEKNIK KLASIFIKASI. Komputer Teknologi Informasi, 4(1). 